\title{
The effect of spatial resolution on the performance of cellular automata- based land use change spatial simulation
}

\section{Bowo Susilo}

Bowo Susilo, "The effect of spatial resolution on the performance of cellular automata-based land use change spatial simulation," Proc. SPIE 11311, Sixth Geoinformation Science Symposium, 1131106 (21 November 2019); doi: $10.1117 / 12.2549048$

EDIE Event: Sixth Geoinformation Science Symposium, 2019, Yogyakarta, Indonesia 


\title{
The Effect of Spatial Resolution on The Performance of Cellular Automata-based Land Use Change Spatial Simulation
}

\author{
Bowo Susilo ${ }^{1}$ \\ ${ }^{1}$ Department of Geographic Information Science, \\ Faculty of Geography, Universitas Gadjah Mada \\ Corresponding author's email: bowosusilo@ugm.ac.id
}

\begin{abstract}
Studies of land use change have been increasingly carried out in recent years. Land use change is seen as one of the fundamental factor for the operation of environmental system from local to global scale. There are various methods to study land use change and cellular automata (CA)-based spatial simulation is a popular one. While this method (CA-based spatial simulation) is widely used in study of land use change, there are many aspects that need to be explored regarding its performance.

Exploring the effect of spatial resolution on CA-based spatial simulation of land use change is the main objective of this research. Yogyakarta urban area was preferred as research area because of its interesting characteristic. Built up land is continuously increasing while agriculture land tend to decrease. Yogyakarta urban area consisted of the city of Yogyakarta and its suburban areas.

Spatial simulation combined with experimental analysis were used as the main methods. CA-based spatial simulation were performed on different scenarios i.e. different spatial resolution of the data input. This study used three different spatial resolution that are $10 \mathrm{~m}, 50 \mathrm{~m}$, and $75 \mathrm{~m}$. Univariate statistical analysis against empirical data of land-use change was conducted to determine those spatial resolutions. Performance of CA-based spatial simulation was accessed using Kappa Index of Agreement (KIA) and two indices of spatial pattern, i.e. variance to mean ratio (VMR) and Moran's I.

This study shows that higher spatial resolution of data input tend to generate a more clustered spatial pattern on the simulated map. The minimum and average value of actual land use change area could be utilized as consideration for determining appropriate spatial resolution. Medium spatial resolution particularly for extended spatial simulation produce more "visually realistic" spatial pattern.
\end{abstract}

Keywords: Spatial Resolution, Simulation, Performance, Cellular Automata, Land Use

\section{INTRODUCTION}

Studies of land use change have been increasingly carried out in recent years. Land use change is seen as one of the fundamental factors for the operation of the environmental system from local to a global scale (Lambin and Geist, 2006). Therefore, many researchers are interested in studying this phenomenon. There are various methods to study land use change and cellular automata (CA)-based spatial simulation is a popular one. While this method is widely used, many aspects need to be explored regarding its performance.

CA has four main components that are; universe, state, neighborhood, and transition rule (Benenzon dan Torens, 2004). The universe is a cell space formed by a discrete set of spatial units called cells. A cell is the smallest unit of spatial simulation which works as an automaton. Each cell has a state or takes a given state from a finite set of possible states. Cell state changes over time according to a finite set of transition rules. The rules are applied to each cell considering the

Sixth Geoinformation Science Symposium, edited by Sandy Budi Wibowo, Andi B. Rimba

Stuart Phinn, Ammar A. Aziz, Proc. of SPIE, Vol. 11311, 1131106 - () 2019 SPIE

CCC code: $0277-786 \mathrm{X} / 19 / \$ 21 \cdot$ doi: $10.1117 / 12.2549048$

Proc. of SPIE Vol. 11311 1131106-1 
neighboring cell. Modification of one or more CA component has been conducted by many researchers to explore the performance of CA-based spatial simulation. (Almeida et al, 2008; Rafsanjani et al, 2013) Among this exploration, very few studies have been reported that address the effects of cell size and configuration on the behaviors of CA-based models (Gundaliya et al, 2005; Chen and Mynett, 2003)

Cells as one of the essential component of CA play an important rule in the spatial simulation of land use change. A cell is a representation of a spatial entity being modeled or simulated. In the study of land-use change, a cell is usually used to represent a certain land parcel. Within a finite time, each land has a certain state e.g. change or persistence (no change). Since the area of land-use change vary across space and time, the size of a pixel used to simulate the change is essential to be considered.

Pixel size, also commonly referred to spatial resolution, has a close association with accuracy. Small pixel size or high spatial resolution data generally considered as high accuracy data. In contrary, large pixel size high spatial resolution data generally considered as low accuracy data. This common perception does not necessarily apply to CA-based spatial simulation. The use of high spatial resolution does not always provide better simulation result. Therefore, the objective of this study is to explore the effect of spatial resolution on CA-based spatial simulation of land use change.

\section{METHODS}

\subsection{Study area}

Yogyakarta urban area (Figure 1) is taken as a study area for conducting a CA-based spatial simulation of land-use change. It is located in the center part of the Province of Yogyakarta Special Region. Yogyakarta urban area was selected because of its interesting characteristic. Land use change in this area, particularly in the suburb is considered intensive. Conversion from agriculture land into built-up land is the major type of land use change in this area. The study area consist of the city of Yogyakarta and it's suburban.

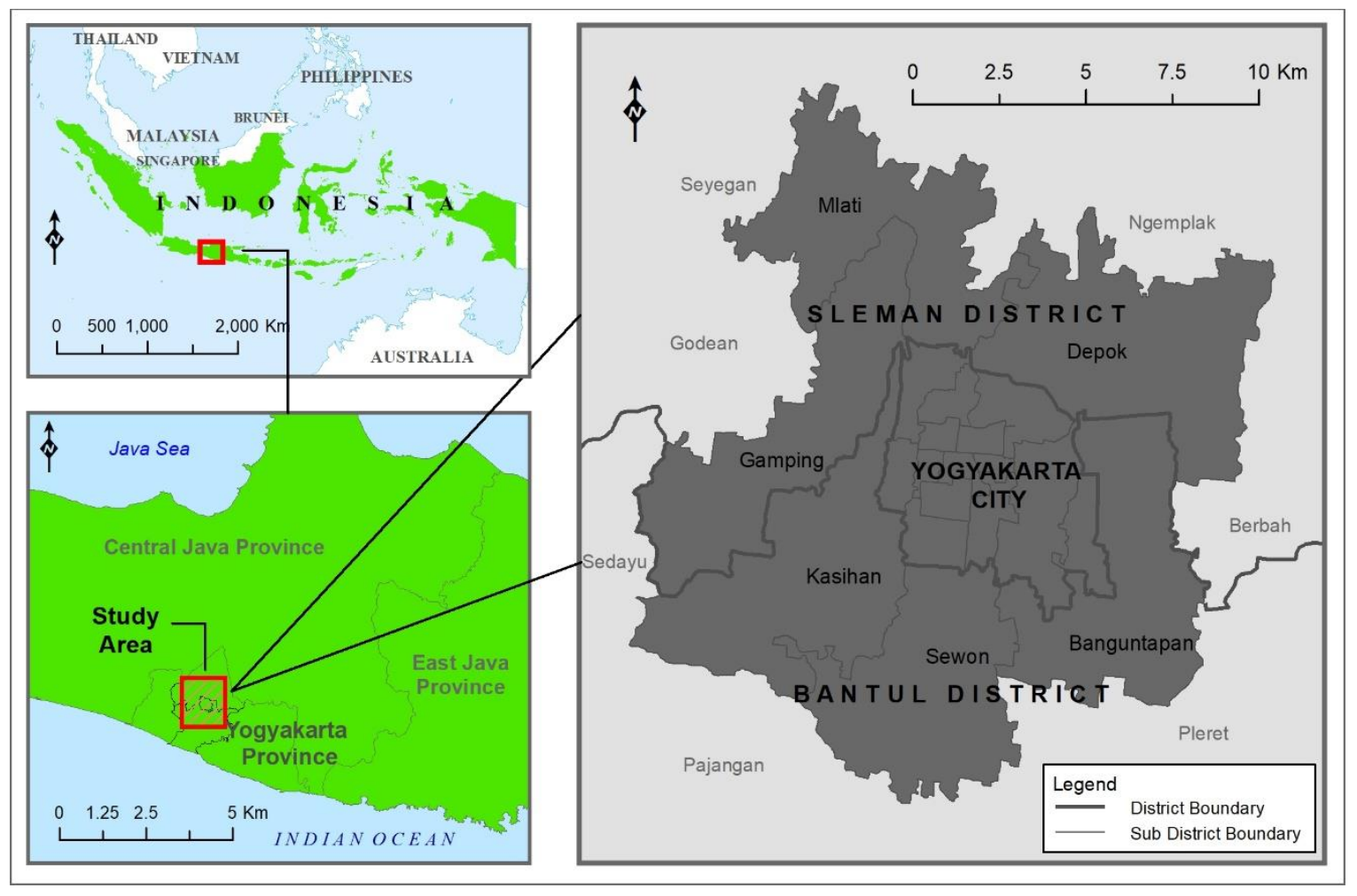

Figure 1: Study area located in the urban area of Yogyakarta 


\subsection{Data}

This study uses a multitemporal land use data as a basis for analysis and simulation of land-use change. The data used were 2000 and 2007 land use maps respectively. Those maps originally derived from 1: 25.000 Indonesian topographic maps and have been updated based on interpretation of remote sensing imagery. Previous study conducted by author using 1993, 2000 and 2007 data has shown that most intensive change had taken place during 2000 and 2007. The spatial data or maps of land use of 2000 and 2007 are already in digital form. Specifically, it was stored in a vector data structure which is an Esri shapefile $(* . s h p)$

\subsection{Analysis of the spatial distribution of land use change}

The location of land use change i.e. the change of land use over space in a certain period is initial information required for this study. This information often referred as to the spatial distribution of land use change. In combination with the quantity of change, this information provides a basis for simulating and predicting the land use change in the future. Spatial distribution of land use change in the study area was analyzed using maps overlay.

The overlay between 2000 and 2007 land use maps provide information on the spatial distribution of land use change from 2000 to 2007. In a raster-based analysis, the overlay commonly performed using the logical expression, i.e. map2000 xor map2007. Image calculator or raster calculator is a common term for tools or menu in raster-based software for conducting map overlay.

\subsection{Determining initial pixel size for CA-based spatial simulation}

Initial pixel size provide a baseline for assessing the effect of pixel size on the performance of CA-based spatial simulation. Therefore, determining the initial pixel size or spatial resolution is a significant step in this study. Unfortunately, kinds of literature related to the initial pixel size are very limited. Initial pixel size in the ecological study is determined based on what so called a principle scale in ecological study. Sometimes, the principle scale is referred to as essential scale. Nevertheless, there are no robust methods for determining pixel size in the study of land use change.

In this study, the initial pixel was determined based on empirical fact related to the area of land use change which took place in the study area. Areas of land use changes were taken from previous analysis, i.e. map overlay. Univariate analysis was performed to obtain a single value that is a minimum, maximum or average area of land use change. The minimum area of land use change in the study area is used as a basis for determining the initial pixel size. Initial pixel size is simply the square root of the minimum area of land use change. For instance, if the minimum area of land use change is $100 \mathrm{~m}^{2}$ then the initial pixel size is $10 \mathrm{~m}$. The second and third pixel size was determined based on the average area of land use change. The same method as determining initial pixel size was applied i.e. took the square root of average and half of the average.

\subsection{Assessment of spatial simulation performance}

The output of a spatial simulation is simply a land use map. The map is frequently referred to as a simulated land use map. Since the simulation was performed using different scenario i.e. different spatial resolution of map input, there were multiple simulated maps produced. Performance of the spatial simulation was assessed based on map comparison analysis. Simulated land use change map compared to actual land use change map and agreement between those maps was calculated. Agreement between simulated and actual land use change map was quantified using Kappa Index of Agreement (KIA) or commonly written as . The definition of $\kappa$ is:

$$
\kappa=\frac{p_{0}-p_{e}}{1-p_{e}}
$$

In equation (1), $p_{0}$ is relative observed agreement among simulated and actual land use change map, and $p_{e}$ is the hypothetical probability of chance agreement.

In addition to KIA, spatial pattern indices were used to compare actual and simulated maps. The indices of the spatial pattern are a variance to mean ratio (VMR) and Moran's I $(I)$. As the name suggests, VMR is a ratio between variance $\left(\sigma^{2}\right)$ and mean $(\mu)$. Variance is calculated using equation (2) while mean is calculated using equation (3). The value of VMR less than 1 indicate regular arrangement, the values of VMR equal 1 indicate random arrangement and the value of VMR more than 1 indicate clustered arrangement (Kimberling et al, 2012). 


$$
\begin{aligned}
\sigma^{2} & =\frac{\sum_{i=0}^{n}\left(x_{i}-\mu\right)^{2}}{N} \\
\mu & =\frac{\sum_{i=0}^{n} x}{N}
\end{aligned}
$$

In the equation (2) and (3), $\sigma^{2}$ is the variance of pixel value, $\mu$ is the mean of pixel value, $n$ denote the number of pixels (land use) category and $\mathrm{N}$ is the total number of pixels. Moran's I is a measure of spatial autocorrelation based on both feature locations and feature values simultaneously. The Moran's index value is between -1 and +1 and used as an indication of spatial clustering. The value near +1 indicates clustering while an index value near -1.0 indicates dispersion. Equation (4) is a base for calculating Moran's index.

$$
I=\frac{\sum_{i=j}^{n} \sum_{j=1}^{n}\left(\operatorname{cov}_{i j} \cdot w_{i j}\right)}{\left(\sigma^{2} \cdot \sum_{i=1}^{n} \cdot \sum_{j=1}^{n} w_{i j}\right)}
$$

In equation (4), $I$ denote Moran's index, cov is the covariance of the feature $i$ and $j, w_{i j}$ is the spatial weight between feature $i$ and $j$, and $n$ is the total number of features.

\section{RESULT AND DISCUSSION}

\subsection{Spatial distribution of land use change}

Information regarding spatial distribution (quantities and locations) of land use change were obtained trough a map overlay. Figure 2 shows the spatial distribution of land use change in the study area. Noted that the focus of this study is change from non-built-up land to built-up land. The quantities of land use change in the study area during 2000 and 2007 were about $655.8 \mathrm{ha}$. Land use changes were distributed almost evenly to the entire of the study area. However, some location tends to possess more intensive changes than the other. Additional information has been attained by overlaying land use change map with administrative boundary map. Table 1 shows detail information about area and the distribution of landuse change by administrative division. Instead of the total area, the table shows univariate statistics of the area of land use change i.e. minimum, maximum and mean (average).

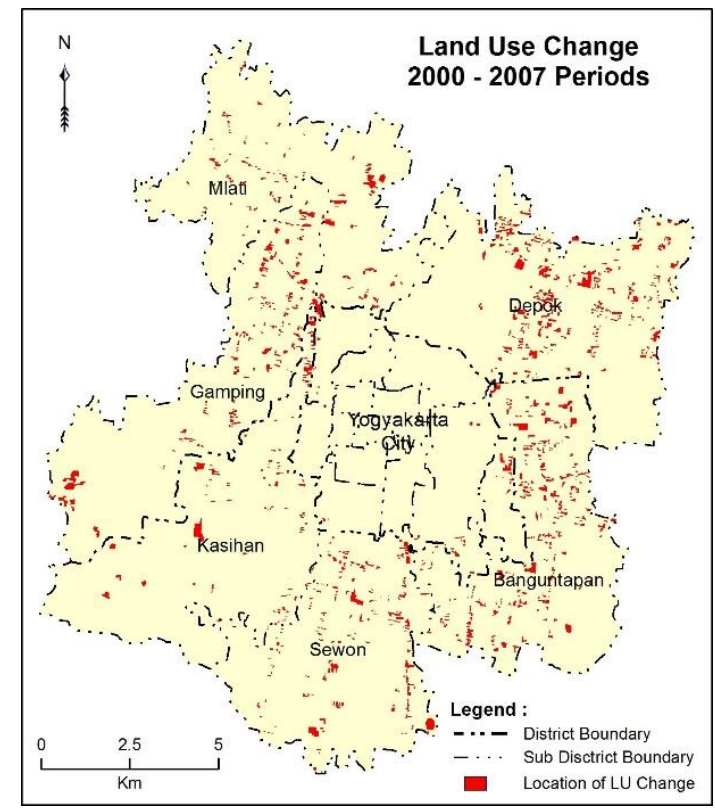

Figure 2: Map shows spatial distribution of land use change between 2000 and 2007 in the study area 
Table 1. Area and distribution of land use change by administrative division

\begin{tabular}{|c|c|c|c|c|c|}
\hline \multirow{2}{*}{ District } & \multirow{2}{*}{ Sub district } & \multicolumn{4}{|c|}{ Area of Land Use Change (m2) } \\
\hline & & Total & Minimum & Maximum & Average \\
\hline \multirow[t]{3}{*}{ Bantul } & Banguntapan & $1,459,394.31$ & 99.6 & $46,898.29$ & $5,084.96$ \\
\hline & Kasihan & $612,418.74$ & 152.4 & $103,684.72$ & $5,372.01$ \\
\hline & Sewon & $964,747.71$ & 123.1 & $71,161.57$ & $4,823.73$ \\
\hline \multirow[t]{3}{*}{ Sleman } & Depok & $1,647,056.76$ & 229.1 & $43,857.18$ & $5,924.65$ \\
\hline & Gamping & $1,054,930.85$ & 97.5 & $118,258.66$ & $6,355.00$ \\
\hline & Mlati & $615,852.36$ & 233.8 & $65,184.37$ & $5,263.64$ \\
\hline \multirow[t]{4}{*}{ Yogyakarta } & Kotagede & $97,517.87$ & 980.3 & $37,553.10$ & $6,501.19$ \\
\hline & Mantrijeron & $7,750.51$ & $1,471.4$ & $6,279.07$ & $3,875.26$ \\
\hline & Tegalrejo & $15,179.38$ & 191.6 & $5,150.96$ & $1,379.90$ \\
\hline & Umbulharjo & $82,656.08$ & 104.0 & $11,029.00$ & $3,593.15$ \\
\hline \multicolumn{2}{|c|}{ Study Area } & $6,557,504.57$ & 99,6 & $118,258.66$ & $5,405.98$ \\
\hline
\end{tabular}

\subsection{Initial pixel size for CA-based spatial simulation}

CA-based spatial simulations of land-use change were conducted using data with different spatial resolution. The initial pixel size or spatial resolution used in this study is $10 \mathrm{~m}$. This value is taken from the square root of $100 \mathrm{~m}^{2}$, which is the minimum area of land use change during 2000-2007 in the study area $\left(99.6 \mathrm{~m}^{2}\right.$ rounded to $\left.100 \mathrm{~m}^{2}\right)$. The other pixel size or spatial resolutions used for simulation were $50 \mathrm{~m}$ and $75 \mathrm{~m}$. Value of $50 \mathrm{~m}$ was obtained from the square root of $2500 \mathrm{~m}^{2}$, which is a proximation of the half of the average area of land use change. The average area of land use change between 2000 and 2007 is $5405 \mathrm{~m}^{2}$ (table 1). Again, proximation was used to determine another pixel size. Taking the square root of $5400 \mathrm{~m}^{2}$ obtained $73.5 \mathrm{~m}$ which then rounded to $75 \mathrm{~m}$.

Figure 3 shows land-use change maps generated using $10 \mathrm{~m}, 50 \mathrm{~m}$ and $75 \mathrm{~m}$ spatial resolution. This is the same map as shown in figure 1, but it has been modified in term of its pixel size or its spatial resolution. It shows the actual land use change between 2000 and 2007. In general, the different spatial resolution still exhibits a similar spatial pattern.
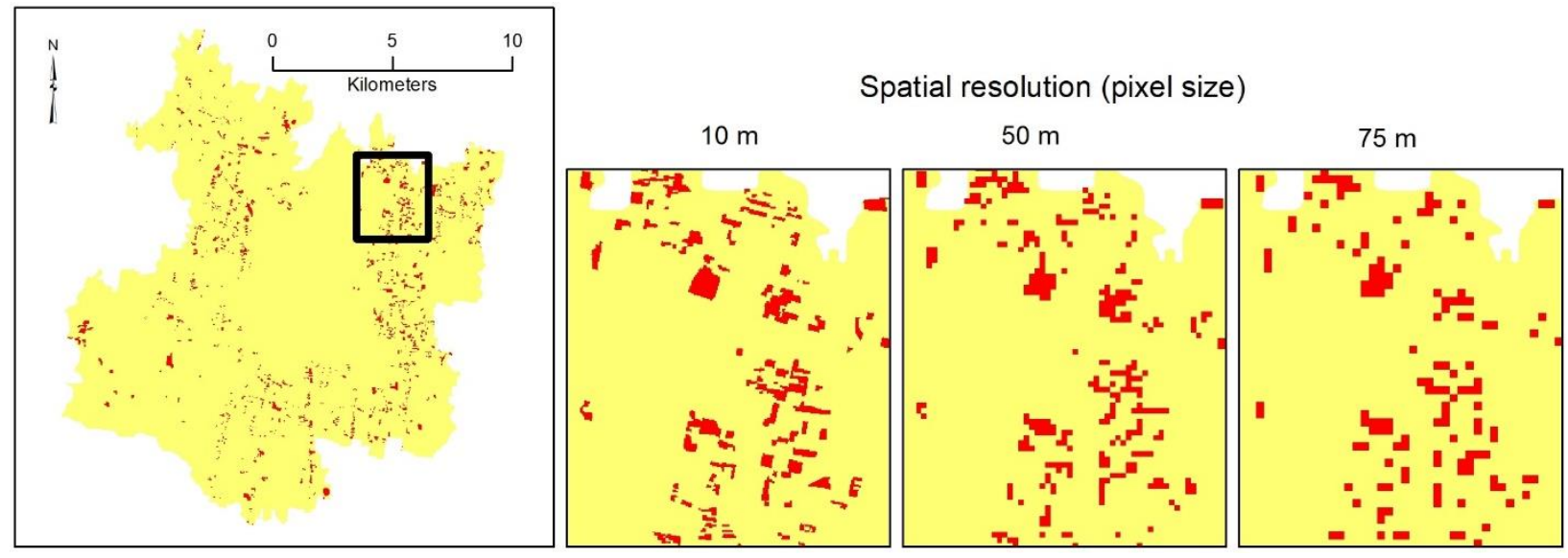

Figure 3: Map of land use change between 2000 and 2007 at different spatial resolution 


\subsection{Spatial resolution and the performance of CA-based spatial simulation}

CA-based spatial simulations of land use change in this study had been done using a certain scenario. Area transition matrix and probability transition map were generated based on the Markov chain principle. The neighborhood was constrained using a 5 x 5 contiguity filter. The initial or beginning time of simulation is the year 2000 and the ending time of simulation is the year 2007. The outputs of the simulations were labeled as simulated land use change maps of 2000-2007. The simulations were extended, for the exploration purpose, to the year 2014 resulting simulated land use change map of 20072014.

Figure 4 provides a visual comparison between actual and simulated land use change between 2000 and 2007. The spatial pattern of the actual and simulated map looks similar. Slightly differences were found in certain locations as shown by blue line circles. This visual assessment is in line with the result of quantitative calculation those are kappa and spatial pattern indices (VMR and Moran's I).

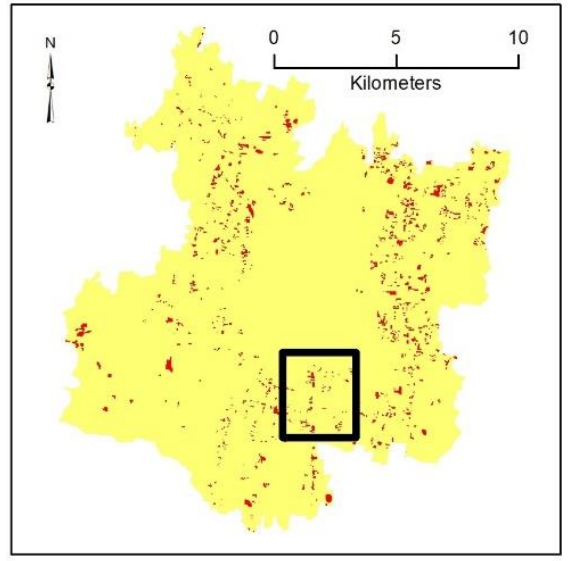

\section{Actual land use change}

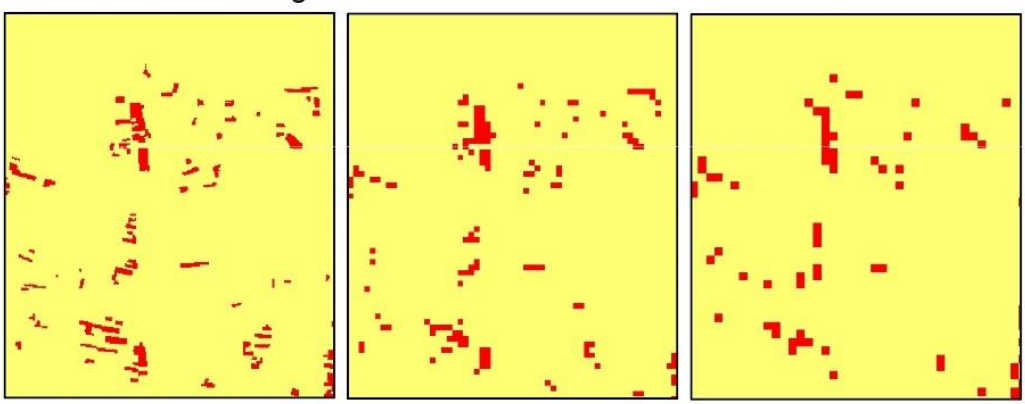

Simulated land use change

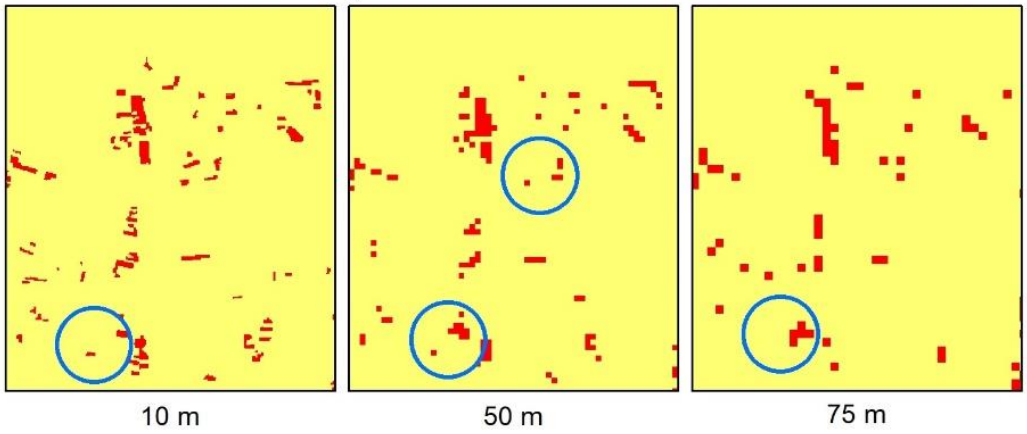

Figure 4: Actual and simulated of land use change map between 2000 and 2007 at different spatial resolution

Table 3 shows the KIA between actual and simulated map at different spatial resolution. Either KIA for each category ( 0 and 1) or overall KIA, all resulted in a similar indication that there is a strong agreement between simulated and actual map. Different indices suggest similar indication as with KIA. The value of VMR and Moran's indicate that actual and simulated map exhibit similar spatial pattern. This indices along with the visual assessment lead to the initial conclusion that the use of different spatial resolution does not affect the performance of the spatial simulation.

Further analysis against the value of Moran's I as shown in table 2, offer additional information about the relationship between spatial resolution and spatial pattern generated from the spatial simulation. The use of higher spatial resolution (smaller pixel size) tends to produce or generate a more clustered spatial pattern. In the opposite, the use of lower spatial resolution (larger pixel size) tends to produce a more dispersed spatial pattern. This indication is demonstrated in the result of the extended spatial simulation (figure 5). 
Table 2. KIA between actual and simulated land use change map at different spatial resolution

\begin{tabular}{cccc}
\hline \multirow{2}{*}{ Spatial Resolution } & \multicolumn{3}{c}{ KIA for Land Use Category } \\
\cline { 2 - 4 } & No Change (0) & Change (1) & Overall \\
\hline $10 \mathrm{~m}$ & 1 & 0.9388 & 0.9684 \\
$50 \mathrm{~m}$ & 1 & 0.9375 & 0.9677 \\
$75 \mathrm{~m}$ & 1 & 0.9354 & 0.9666 \\
\hline
\end{tabular}

Extended spatial simulation offers different insight on the effect of spatial resolution to spatial simulation performance. This simulation used information obtained from 2000 and 2007 land use maps to generate a simulation of land use change from 2007 to 2014. Therefore this simulation is termed as extended spatial simulation. Figure 5 shows simulated land use change maps from 2007 to 2014 at different spatial resolution.

Table 3. Spatial pattern indices of actual and simulated land use change map at different spatial resolution

\begin{tabular}{llrrr}
\hline \multirow{2}{*}{ Spatial Pattern Indices } & Land Use Change & \multicolumn{3}{c}{ Spatial Resolution } \\
\cline { 3 - 5 } & Map & \multicolumn{1}{c}{$10 \mathrm{~m}$} & \multicolumn{1}{c}{$50 \mathrm{~m}$} & \multicolumn{1}{c}{$75 \mathrm{~m}$} \\
\hline \multirow{2}{*}{ Variance to Mean Ratio } & Actual & 0.969256 & 0.968978 & 0.968943 \\
& Simulated & 0.971082 & 0.970861 & 0.970893 \\
\hline \multirow{2}{*}{ Moran's I } & Actual & 0.8011 & 0.3466 & 0.2205 \\
& Simulated & 0.7984 & 0.3398 & 0.2157 \\
\hline
\end{tabular}
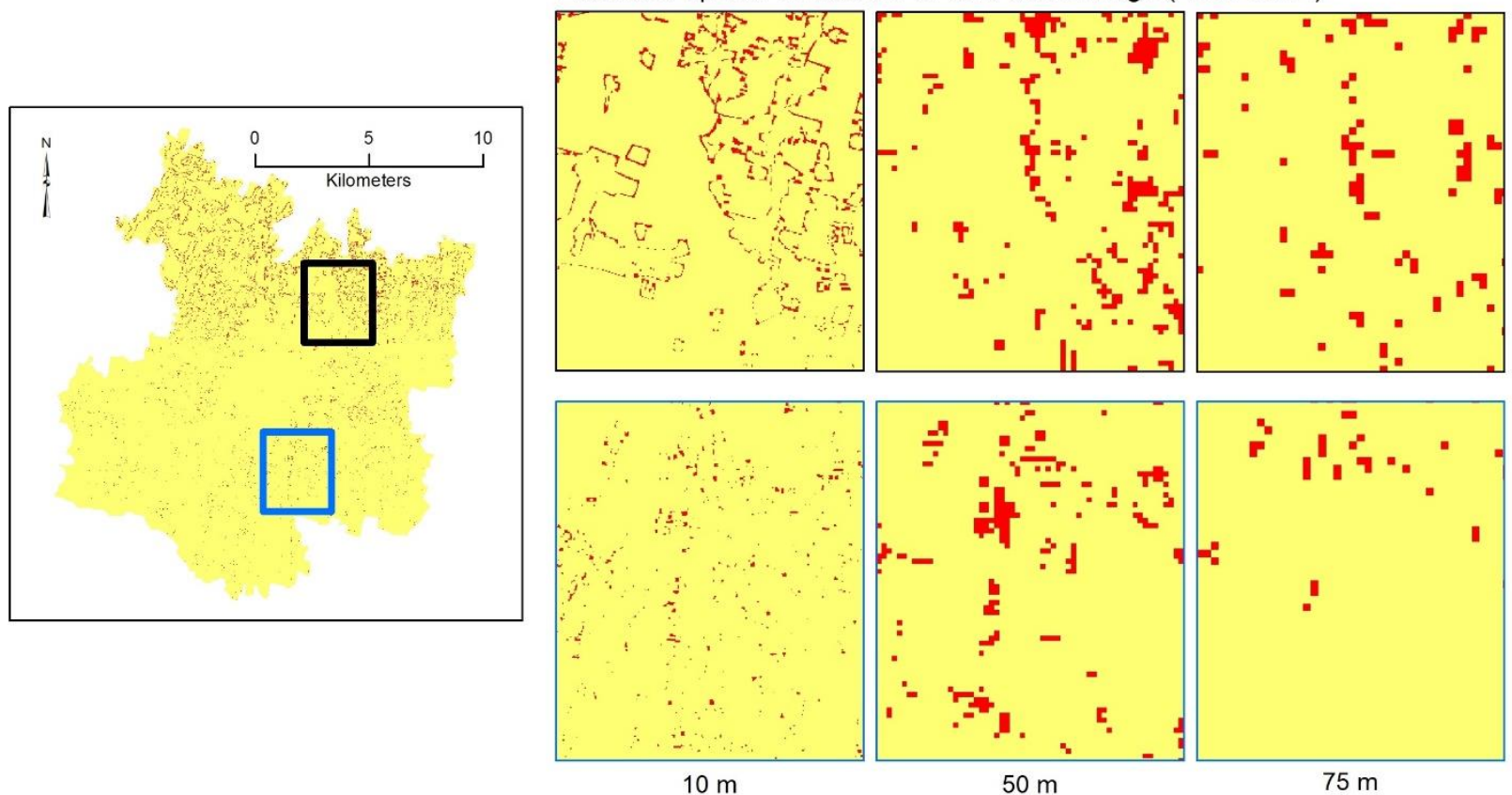

Figure 5: Simulated of land use change map 2007-20014 at different spatial resolution 
Since the map of actual change from 2007 to 2014 was not available or not prepared yet, map comparison is only available among simulated map with different spatial resolution. As seen in figure 5, simulation using $50 \mathrm{~m}$ spatial resolution generate more "realistic" spatial pattern rather than simulation using $10 \mathrm{~m}$ and $75 \mathrm{~m}$. Visual assessment of figure 5 leads to additional indication related to the effect of spatial resolution on the performance of the spatial simulation. The use of high spatial resolution in CA-based spatial simulation does not necessarily generate a better result. Instead of using high spatial resolution without proper consideration, certain assessment should be conducted to determine appropriate spatial resolution. Analysis of empirical data provide better consideration for choosing appropriate pixel size or suitable spatial resolution to be used in CA-based spatial simulation.

\section{CONCLUSION}

Spatial resolution or pixel size is considered an essential aspect affecting the performance of CA-based spatial simulation. A simple experiment in this study shows the effect of spatial resolution on the performance of CA-based spatial simulation particularly for simulation of land-use change. The use of higher spatial resolution (small pixel size), tend to produce or generate a more clustered spatial pattern on the simulated map. The appropriate spatial resolution could be determined by conducting such an exploratory analysis, i.e. univariate statistical analysis. This study shows, the minimum and average value of actual land use change area could be utilized as consideration for determining appropriate spatial resolution. Medium spatial resolution particularly for extended spatial simulation produce more "visually realistic" spatial pattern.

\section{REFERENCES}

[1] Almeida, C.M., Gleriani, J.M., Castejon, E.F. and Filho, B.S.S., "Using Neural Networks and Cellular Automata for Modelling Intra-Urban Land-Use Dynamics," International Journal of Geographical Information Science, Vol. 22, No. 9, p: 943-963 (2008)

[2] Arsanjani, J.J., Helbichb, M., Kainza, W., and Boloorani, A.D., "Integration of Logistic Regression, Markov Chain and Cellular Automata Models to Simulate Urban Expansion", International Journal of Applied Earth Observation and Geoinformation, No 21 p 265-275. (2013)

[3] Benenson, Itzhak dan Torrens, P.M., [Geosimulation: Automata-based Modeling of Urban Phenomena], Jhon Willey and Sons Ltd, England (2004).

[4] Chen, Q. and Mynett, A.E., "Effects of cell size and configuration in cellular automata based prey-predator modelling," Simulation Modelling Practice and Theory no 11, pp:609-625 (2003)

[5] Gundaliya, P.J., Mathew, T.V., and Dhingra, S.L., "Methodology for finding optimum cell size for a grid based cellular automata traffic flow model," European Transport no 29 pp: 71-79 (2005)

[6] Kimberling, A.J., Buckley, A.R., Muehrcke, P.C. and Muehrcke, J.O., [ Map use: reading, analysis, interpretation. Seventh Edition], Esri Press 380 New York (2012)

[7] Lambin, E.F., dan Geist, H.J., [Land-Use and Land-Cover Change: Local Processes and Global Impacts], Springer New York (2006).

[8] Verburg, P.H., de Koning, G.H.J., Kok, K., Veldkamp, A., and Bouma, J., "A Spatial Explicit Allocation Procedure for Modelling The Pattern of Land Use Change Based Upon Actual Land Use", Ecological Modelling 116 (1999) 45-61 (1999) 